\title{
La crisis social: reflexión teológica sobre las desigualdades
}

\author{
FERNANDO VERDUGO* \\ Pontificia Universidad Católica de Chile (Chile) \\ fverdugor@uc.cl
}

\begin{abstract}
Resumen
El malestar frente a las desigualdades, sobre todo aquellas que hieren la convivencia humana, han dado curso últimamente a diversas formas de manifestación social en el mundo entero, incluyendo algunas marcadas por la violencia. Sin embargo, ni las desigualdades ni los estallidos sociales son nuevos en la historia de la humanidad. Este trabajo, luego de dar cuenta de algunos estudios sociales recientes en torno a las desigualdades que dañan a las personas y a las sociedades, realiza una aproximación teológica y magisterial a este drama, se hace cargo nuevamente de los valores evangélicos como la justicia y equidad. Termina ofreciendo algunas conclusiones o reflexiones finales que contribuyan al debate y al curso de la acción transformadora que demanda el presente.
\end{abstract}

Palabras claves: desigualdades injustas; igualdad; violencia; diálogo político; paz.

\section{Social crisis: theological reflection on inequalities}

\begin{abstract}
The unease in the face of inequalities, especially those that harm buman coexistence, have recently given rise to various forms of social manifestation throughout the world, including some marked by violence. However, neither inequalities nor social outbursts are new in the history of humanity. This work, after reviewing some recent social studies on inequalities that harm people and societies, makes a theological and magisterial approach to this drama. It goes back again to evangelical values such as justice and equity. It ends by offering some conclusions or final reflections that would like to contribute to the debate and the course of the transformative action that the present demands.
\end{abstract}

Key words: unjust inequalities; equality; violence; political dialogue; peace.

Doctor en Teología. Profesor y Director de Postgrado de la Facultad de Teología de la Pontificia Universidad Católica de Chile. Entre sus publicaciones recientes, cabe destacar: "Desigualdad, violencia y paz en la conferencia de Medellín. Perspectiva teológico-cultural" (2019); "Relectura de Medellín: desafíos actuales para la Teología", (2018); "La educación teológica en el contexto latinoamericano" (2016); "Perspectivas teológicas de la Encíclica Laudato si” (2015). 


\section{INTRODUCCIÓN $^{1}$}

Con ocasión de la crisis o "estallido social" que afectó a Chile con inusitada intensidad a partir de octubre del 2019, diversos análisis políticos, sociales y económicos han puesto la atención en la desigualdad como una de las principales causas del fenómeno. Las desigualdades en los ingresos, en el acceso a la salud, a la justicia y a la educación de calidad, en las pensiones de los jubilados, en términos de género, en la configuración territorial de la ciudad, etc.; desigualdades cultivadas y mantenidas por largo tiempo, parecen explicar la vehemencia e incluso violencia con que amplios sectores de la sociedad han expresado su descontento con el status quo.

La desigualdad, sobre todo aquella que hiere la convivencia humana, no es un problema que inquieta solo a la sociedad chilena. Preocupa en el mundo entero y ha sido objeto de atención tanto desde el ámbito político, el académico y el eclesial. En este trabajo me propongo, en primer lugar, dar cuenta de algunos estudios que se han realizado en torno a la desigualdad, a nivel mundial y local, para luego detenerme, en un segundo momento más extenso, en algunos hitos bíblicos, teológicos y magisteriales y, enseguida, proponer algunas conclusiones o reflexiones finales que contribuyan al debate y al curso de la acción transformadora que demanda el presente. Obviamente, dada la complejidad de la cuestión aquí abordada, de las distintas aproximaciones disciplinares e ideológicas en juego, el esfuerzo aquí realizado no puede ser sino limitado. Por otra parte, dado el contexto en el que se ha agudizado la discusión sobre las desigualdades, el vínculo con la violencia no puede ser soslayado.

\section{Aproximaciones DeSDe las CIENCIAS SOCIALES A LAS DESIGUAL- DADES}

Es este apartado, de manera muy somera, recogeremos algunos análisis sobre el fenómeno de las desigualdades, consideradas sobre todo desde la economía, de la historia y las ciencias sociales, tanto en estudios globales como locales.

El historiador económico y social Walter Scheidel, en un estudio de largo aliento publicado en español hace un par de años (2018), inicia su

1 Este artículo se elaboró a partir de la ponencia presentada en el Seminario Interno de Profesores de la Facultad de Teología de la Universidad Católica de Chile, el día 6 de octubre de 2020. Luego de la crisis social desencadenada en Chile en octubre del 2019, el tema escogido para el Seminario anual fue "El despertar de Chile": abordaje teológico de la crisis presente y de las transformaciones futuras. 
monumental obra mostrando como la brecha entre ricos y pobres se torna cada vez mayor y más peligrosa. Como ejemplo preliminar, señala que en el año 2015 las setenta y dos familias más ricas del planeta eran propietarias de tanta riqueza personal neta como la mitad más pobre de la humanidad; es decir, 3.500 millones de seres humanos. Los desequilibrios que se dan a nivel mundial, se replican también al interior de las sociedades o países. Los datos y estadísticas que aporta son abrumadores. Pero lo más perturbador de su documentado análisis, que considera miles de años y distintas sociedades y continentes, consiste en que la violencia y algunas desgracias han sido el gran factor que ha contribuido a nivelar las desigualdades emergentes a lo largo de la historia. En efecto, la civilización no se ha prestado para nivelaciones pacíficas en sus años de existencia. Al contrario, en épocas de estabilidad, las desigualdades no han hecho más que aumentar hasta niveles que acaban siendo insostenibles, al punto de desembocar en asaltos igualitaristas abruptos. Parafraseando al libro de Apocalipsis de la Sagrada Escritura, Scheidel denomina "los cuatro jinetes de la equiparación" a las guerras con movilizaciones masivas (la Primer y Segunda guerra mundial, por ejemplo), a las revoluciones transformadoras (la francesa, la rusa, la china, etc.), a los fracasos o colapsos de los Estados (Egipto antiguo, Mesopotamia, el Imperio Romano, Somalia) y, también, a las grandes epidemias que mermaban la población, generando escasez de mano de obra y aumentado su precio. De este modo, directa o indirectamente, se aplanaban las desigualdades que solían incrementarse en tiempos de paz. De ahí que, para el autor, comprender esas "fuerzas niveladoras" que han surgido en la historia pasada parece crucial para adoptar políticas y medidas concretas que nos permitan combatir pacíficamente la desigualdad en el presente y futuro.

En todo caso, para este historiador austríaco radicado en Estados Unidos, la actual pandemia del coronavirus no se vislumbra como un "gran nivelador" al estilo de la peste negra en Europa. En una reciente entrevista (Fuentes, 2020), Scheidel señala:

La actual pandemia es diferente, porque incluso en el peor de los escenarios, la pandemia de coronavirus matará a una proporción mucho menor de la población respecto de las grandes epidemias del pasado. Como resultado, no habrá escasez de mano de obra y los salarios de los trabajadores comunes no aumentarán. Solo por esta razón, no se convertirá en un nivelador verdaderamente excelente. $E$ incluso si la mortalidad fuera mucho mayor, como podría ser en una futura epidemia, la inteligencia artificial y la automatización podrían absorber parte de la escasez de mano de obra resultante y mantener bajo el valor del trabajo humano. 
Con todo, en la línea de la tesis de su obra, considera que podrían darse condiciones para un nuevo brote de violencia, el cual podría evitarse si se adoptan medidas políticas adecuadas. En efecto,

la crisis también tiene el potencial de aumentar la presión política a favor de un cambio más progresivo. Si la flexibilización cuantitativa logra mantener a flote las economías y los avances médicos nos permiten contener el virus, podemos presenciar el regreso a alguna versión de los negocios como de costumbre, con todas las desigualdades arraigadas que esto conlleva. Pero si la crisis resulta ser más prolongada, si conduce a una depresión global o si las vacunas se retrasan mucho, la miseria popular y el descontento podrían llegar a niveles tales que las decisiones políticas más radicales se vuelvan más atractivas o incluso inevitables. Esto podría incluir intervenciones tales como nacionalizaciones de industrias privadas, esquemas de ingresos básicos universales y una tributación más alta y progresiva de los ricos. Esto, a su vez, podría reducir la concentración de ingresos y riqueza.

Cabe destacar también la obra del economista francés Thomas Piketty, El capital en el siglo XXI (2014), donde el autor postula, apelando no solo a estudios económicos sino, también a la historia, a la política y a otras ciencias sociales, que el capitalismo tiene la tendencia a producir desigualdades y aumentarlas. La tesis del libro es la siguiente:

Cuando la tasa de rendimiento del capital supera de modo constante la tasa de crecimiento de la producción y del ingreso -lo que sucedía hasta el siglo XIX y amenaza con volverse la norma en el siglo XXI-, el capitalismo produce mecánicamente desigualdades insostenibles, arbitrarias, que cuestionan de modo radical los valores meritocráticos (...) y -dirá más adelante- los principios de justicia social que son el cimiento de nuestras sociedades democráticas. (Piketty, 2014: 14 y 39).

Para Piketty, esta desigualdad fundamental "nada tiene que ver con una imperfección del mercado; muy por el contrario: mientras más 'perfecto' sea el mercado del capital, en el sentido de los economistas, más posibilidades tiene de cumplirse la desigualdad" (Piketty, 2014: 39). No es, pues, en el mercado donde hay que buscar las soluciones. Luego de documentar el gigantesco incremento de las desigualdades patrimoniales mundiales, y de estudiar los "treinta gloriosos" años que siguieron a la Segunda Guerra Mundial, donde las desigualdades parecieron reducirse, intenta sacar fórmulas que permitan superar el capitalismo entregado a su propia inercia. Para este economista, "sólo un impuesto progresivo sobre el capital cobrado a nivel mundial (o por lo menos en zonas económicas 
regionales bastante importantes, como Europa o América del Norte) permitiría contrarrestar eficazmente semejante dinámica" (Piketty, 2014: 449). Además, es necesario un control democrático, de modo que esa dinámica no se torne creciente y explosiva sino, más bien, haciendo uso de la herramienta impositiva sobre el capital (preferible, pero no excluyente del impuesto progresivo sobre el ingreso) pueda utilizarse desde un Estado Social que promueva una verdadera igualdad de oportunidades, que favorezca los proyectos comunes como educación, salud, jubilación, empleo, desarrollo sostenible, etc. (Piketty, 2014: 502).

Buscando nuevas vías para superar el capitalismo generador de crecientes desigualdades, Thomas Piketty en su nuevo libro titulado Capital e Ideología (2019) retoma y profundiza el tema desde una perspectiva histórica, económica, política y sociológica. Con nuevos antecedentes, como los que aporta el World Inequality Database, ofrece una visión menos occidental o eurocéntrica y amplía el estudio hacia más países y a todos los continentes. De este modo, radicaliza su crítica y busca superar un sistema que acrecienta las desigualdades y constituye una amenaza para el planeta. No reduce el estudio al drama de la concentración de la tenencia de la propiedad, del capital y los activos de un país, sino también a las inequidades en el ámbito de la educación, a las diferencias que existen entre países en cuanto la recaudación de fondos mediante impuestos. A partir del estudio exhaustivo y análisis, considera que "es posible construir un relato más equilibrado y esbozar el contorno de un nuevo socialismo participativo para el siglo XXI" (Piketty, 2019: 13). Frente a un determinismo económico, Piketty vuelve a darle importancia a las ideologías y a la política; éstas están al origen de las desigualdades y pueden incidir, también, en su superación histórica. Es posible, sostiene, construir sociedades justas donde todos sus miembros puedan acceder a los bienes fundamentales, como la educación, salud, empleo, participación en la vida social, cultural, política, etc. Para que sea posible, insiste nuevamente en la recaudación fiscal justa, que combine un sistema progresivo de impuestos sobre las sucesiones, la renta y el patrimonio. La principal novedad de su propuesta en esta obra, estaría en la implantación de un impuesto anual y altamente progresivo sobre la propiedad, que permita financiar la dotación de capital para cada joven adulto, y así desplegar una forma de propiedad temporal y de circulación permanente de los patrimonios (Piketty, 2019: 689).

Además de estas obras de gran envergadura aquí muy sucintamente reseñadas, las cuales intentan explicar el origen y desarrollo de las desigualdades, sobre todo económicas, como también las fuerzas niveladoras ocurridas en el mundo y en la historia, y de proponer, además, posibles estrategias para la superación de tales males, como los impuestos 
progresivos al capital y la prioridad a la política por sobre la economía, conviene detenerse en el escenario más local. Para ello nos sirve el estudio del PNUD Chile, Desiguales. Orígenes, cambios y desafios de la brecha social en Chile ${ }^{2}$. Para nuestro propósito, cabe destacar que esta exhaustiva investigación multidisciplinar fue publicada un par de años antes del estallido social en Chile; es decir, las diversas formas de desigualdad que afectan a nuestro país, como a otros países de la región, estaban siendo objeto de atención desde hace un buen tiempo.

Si bien, desde la recuperación de la democracia Chile ha logrado importantes avances en términos institucionales y en la superación de la pobreza $^{3}$, a la siga de un crecimiento económico sostenido, poniéndolo en primer lugar en la región; sin embargo, el progreso alcanzado no alcanza a todos por igual. La desigualdad en términos de ingreso también lo pone en los primeros lugares del ranking latinoamericano ${ }^{4}$.

Cabe destacar la definición de "desigualdad" con la que opera el documento: se trata de "las diferencias en dimensiones de la vida social que implican ventajas para unos y desventajas para otros, que se representan como condiciones estructurantes de la vida, y que se perciben como injustas en sus orígenes o moralmente ofensivas en sus consecuencias, o ambas" (PNUD Chile, 2017: 10). Se trata de desigualdades que van más allá de las brechas en los ingresos, aunque éstas no dejan de ser inquietantes.

2 Tanto el informe completo del PNUD Chile, de 411 páginas, como la síntesis, de 36 páginas, están disponibles en internet: https://www.cl.undp.org/content/chile/es/home/library/poverty/desiguales-origenes--cambios-y-desafios-de-la-brecha-social-en-.html. Para este trabajo, nos servimos de la Síntesis.

3 "Usando la medida de pobreza introducida por el Ministerio de Desarrollo Social en 2013, y aplicándola a los datos históricos, se tiene que desde 1990 a la fecha el porcentaje de personas viviendo en la pobreza se ha reducido de un $68 \%$ a un $11,7 \%$. Solo en los últimos quince años, el ingreso per cápita real de los hogares en el 10\% más pobre de la población creció en un 145\% real. (...) Si bien el nivel absoluto de ingresos es aún bajo para una gran mayoría, el cambio relativo respecto del propio pasado es indudablemente muy significativo" (PNUD Chile, 2017: 11).

4 En Chile, si bien ha habido disminución en la desigualdad de ingreso desde el 2000 al 2015 (GINI de 54,9 a 47,6), debido a la reducción de la brecha de salarios entre los trabajadores de mayor y menor calificación y las transferencias gubernamentales a los grupos pobres y vulnerables, llama la atención la concentración de ingreso y riqueza en el 1\% más rico: capta el 33\% del ingreso que genera la economía chilena. La concentración en el tope contribuye a la percepción de que las distancias no se acortan (PNUD Chile, 2017: 13-14). Sobre todo, si en el 2015, la mitad de los asalariados del país, con jornada de 30 o más horas semanales, obtenía un salario bajo: es decir, insuficiente para cubrir las necesidades básicas de un hogar promedio (p. 15); o bien, si la mitad de los jubilados percibe hoy una pensión inferior al 70\% del salario mínimo (p. 17). 
En efecto, como se puede apreciar a lo largo del documento, que cuenta con los mejores datos disponibles y con evidencia cuantitativa y cualitativa generada para la investigación, si bien se focaliza en las desigualdades que tienen su origen en lo socioeconómico, estas abarcan también la educación, el acceso a la salud, al poder político ${ }^{5}$; el respeto y dignidad con que son tratadas las personas ${ }^{6}$; en la atención que se da al origen por sobre el mérito de las personas, etc. Las primeras víctimas son las mujeres ${ }^{7}$, las regiones en relación al centro, los pueblos originarios y otras minorías ${ }^{8}$. El Informe presenta, pues, con claridad que la desigualdad socioeconómica es un fenómeno multidimensional y dinámico. Todo lo cual debilita al sistema democrático, constituye una amenaza a la cohesión social y a la convivencia pacífica, tal como lo ha quedado de manifiesto en octubre del 2019, y en estos momentos no sabemos qué vendrá después de la pandemia. Finalmente, digamos que el Informe se detiene y analiza ciertos "nudos" que reproducen la desigualdad socioeconómica y que es necesario desatar para reducirla e impulsar cambios sostenibles en el tiempo. Entre otros, la concentración del capital y los ingresos, como tendencia creciente, y "que explica entre otros hechos la inconsistencia que hay entre el elevado ingreso per cápita del país y el bajo nivel de vida de la mayoría de la población" (PNUD Chile, 2017: 29). En fin, reducir las desigualdades en todos los ámbitos se plantea no

5 En Chile se da una concentración del poder político y sobrerrepresentación de los grupos de mayores ingresos en los espacios de toma de decisiones. De ahí la importancia de cambios en la institucionalidad política que podría inducir correlaciones de fuerza relativamente más igualitarias que las actuales (PNUD Chile, 2017: 31-33).

$6 \quad$ Según el Informe: "en Chile se evidencia una fuerte 'desigualdad del trato social'. $\mathrm{El}$ análisis muestra que pertenecer a las clases más acomodadas facilita significativamente no tener experiencias de malos tratos, una ventaja considerable cuando lo que está en juego son las formas de reconocimiento social desde las cuales las personas pueden desplegar su subjetividad" (PNUD Chile, 2017: 19). También se constata que "la molestia frente a la desigualdad se concentra en las desigualdades de acceso a la salud y la educación, y que a algunas personas se las trate con mayor respeto y dignidad que a otras" (p. 20). Todo ello ha incrementado, en los últimos quince años, la percepción de injusticia (p. 21).

A nivel de salarios, por ejemplo: "Las trabajadoras tienen una probabilidad 10 puntos superior que los hombres de recibir una paga baja, que aumenta a 20 puntos en el segmento de trabajadores con estudios secundarios" (PNUD Chile, 2017: 23). O bien, la mayor inseguridad que experimentan las mujeres, debido a la menor cobertura y montos de las pensiones que reciben (p. 17).

8 Con una mirada histórica, constata que "la desigualdad socioeconómica en Chile ha tenido una connotación étnica y racial. Las clases altas se configuraron como predominantemente blancas, mientras que mestizos e indígenas ocuparon un grado más bajo en la jerarquía social, y negros y mulatos uno aun más bajo" (PNUD Chile, 2017: 34). 
sólo como un desafío ético, sino también una condición de posibilidad para un desarrollo sostenible e inclusivo.

\section{APROXIMACIÓN TEOLÓGICA A LAS DESIGUALDADES INJUSTAS E HIRIENTES}

En este apartado, nos proponemos realizar una aproximación teológica al concepto o valor de la igualdad y, sobre todo, al drama humano que puede significar su antónimo, la desigualdad. Dadas las posibilidades que tenemos, me limitaré a algunos tópicos o hitos bíblicos, teológicos y magisteriales. Ciertamente debería ampliarse la indagación hacia otros temas o paradigmas afines, como la justicia y la injusticia, la pobreza y la riqueza, la inclusión y la exclusión, etc. que tienen largas resonancias bíblicas y magisteriales, pero obviamente implica un mayor espacio del que disponemos. Habiendo muchas opciones temáticas y metodológicas, me propuse comenzar por el concepto de "igualdad", porque la lingüística y la semiótica nos ha enseñado a estar atentos al eje paradigmático de los mensajes que circulan en las culturas; es decir, a los esquemas de diferencias que subyacen en los discursos. Se habla o escribe más sobre la desigualdad, y menos sobre la igualdad. Me pareció interesante, entonces, partir por este último significante del eje paradigmático igualdad/desigualdad y desde allí moverme, enseguida, hacia algunas consideraciones teológicas y magisteriales. Espero que este ejercicio teológico sea una contribución en la necesaria atención que requieran las desigualdades que hoy día hieren a la humanidad y a nuestra sociedad, en particular. Por modesto que sea este ejercicio de discernimiento en medio de los turbulentos acontecimientos del presente, nos anima la esperanza formulada por el Concilio Vaticano II (1965) en la constitución Gaudium et spes, de que "la fe [...] orienta la mente hacia soluciones plenamente humanas" $\left(n^{\circ} 11\right)$.

\subsection{La igualdad como valor}

Para nuestra sorpresa, el sustantivo "igualdad", como su antónimo "desigualdad", prácticamente no aparecen en la Sagrada Escritura. Pero cuando lo hace, es elocuente. En efecto, tan sólo en una carta de San Pablo aparece la palabra igualdad, en el contexto de una colecta en favor de los cristianos de Jerusalén (2 Co 8,1-15; sobre la colecta, ver Rom 15,25-28 y 1 Co 16,1). El apóstol motiva a los cristianos de Corinto a ser generosos para salir en ayuda de los necesitados y hacer que, de este modo, exista igualdad entre los creyentes. Pablo precisa, sin embargo: "No se trata de que paséis apuros para que otros tengan abundancia, sino de 
procurar la igualdad. Ahora, vuestra abundancia remedia su necesidad, para que, en otro momento, su abundancia pueda remediar vuestra necesidad, y así reine la igualdad" (2 Co 8,13-14).

Es interesante notar que para San Pablo no se trata solo de ayudar a los que carecen de algún bien, sino de alcanzar un objeto-valor que denomina igualdad (íó் $\tau$ ). Ese objeto-valor buscado es resultado de la transferencia generosa de bienes que, según Rom 15,27, pueden ser "espirituales" y "temporales", por parte de los que tienen hacia los que no tienen o tienen poco. Pablo motiva la generosidad de los corintios apelando al testimonio que han dado los cristianos de Macedonia (2 Co 8,23) pero, sobre todo, a Jesucristo mismo, "el cual, siendo rico, se hizo pobre por vosotros para enriqueceros con su pobreza" (2 Co 8,9$)$. Es decir, el fundamento de la generosidad que tiende hacia la igualdad es, en última instancia, cristológico.

Para Pablo, Jesucristo no solo es ejemplo o motivación última para la generosidad orientada a lograr la igualdad entre los cristianos o "santos", como los llama. La muerte y resurrección de Jesucristo es también causa de que todos los seres humanos, en cuanto hijas e hijos de Dios, sean iguales en dignidad. En efecto, por la fe en el misterio pascual sellada mediante el bautismo, "ya no hay judío ni griego; ni esclavo ni libre; ni hombre ni mujer, ya que todos vosotros sois uno en Cristo Jesús" (Gal 3,28 ). Así, la igualdad a la que estamos llamados no es solo cuantitativa, en términos de bienes, sino también cualitativa, en términos de dignidad: ni la raza, ni el status de ciudadano, ni el género debieran atentar contra la igualdad fundamental de las hijas e hijos de Dios, en Cristo Jesús.

Así, pues, para las cristianas y cristianos la fe en Jesucristo es el fundamento para promover la igualdad entre todos los seres humanos. El desarrollo teológico posterior, tanto del misterio de la encarnación como del misterio pascual, no han hecho sino explicitar aún más dicho fundamento. Pensemos, por ejemplo, en la teología de la divinización desarrollada por los Padres: en Cristo, Dios se hace hombre, para que el ser humano participe de su divinidad. O bien, en la teología de la justificación por la fe, sustentada en el amor reconciliador de Dios manifestado en la cruz de Cristo (ver 2 Co 5,19), que liberara al ser humano "de la obsesión constante por su propio valer. Y solo el hombre liberado de esa obsesión puede mirar a los otros como iguales" (González Faus, 2015).

\subsection{Los valores de Jesús de Nazaret}

Además de los incipientes desarrollos cristológicos que hemos recogido en San Pablo para fundamentar la igualdad entre los seres humanos, 
es preciso poner atención en el carácter revelador de la vida misma de Jesús, de su mensaje, obras y palabras, como de hecho lo hacen muchas de las cristologías contemporáneas y algunas latinoamericanas, en particular. Allí encontramos, también, el propósito y modo de proceder Jesús para hacer que, en términos de Pablo, "reine la igualdad". En definitiva, no se trata solo de creer en Jesucristo, sino de que continúe también en la historia la fe de Jesucristo. Es decir, que sigan marcando la historia aquellos valores por los cuales Jesús se jugó la vida. Como bien observa el teólogo uruguayo Juan Luis Segundo (1991), Jesús de Nazaret como ser humano tiene los mismos componentes que conforman nuestra existencia. Y nos habla desde ellos. Es decir, hay en su vida obvios elementos de fe, en sentido antropológico de la palabra, pues apuesta por unos valores que le dan orientación a su existencia. Hay también unas mediaciones sin las cuales sus valores habrían quedado sin plasmarse en la realidad. Y, finalmente, cuenta con datos trascendentes sobre las posibilidades últimas del ser humano y del mundo, que marcan su vida y aun su manera peculiar de morir. Segundo está convencido que atendiendo a esas dimensiones presentes en Jesús, como en todo ser humano, puede contribuir a "repensar la posible relevancia de ese personaje histórico que es Jesús de Nazaret para cualquier hombre que busque dar sentido (o un mejor sentido) a su vida", tanto personal como social (1991: 36).

Una fe religiosa en Jesús comporta el convencimiento de que el sistema de valores adoptada por la fe de Jesús tiene relación con Dios y su revelación. En efecto, "desde que Dios no entra en nuestra experiencia sensible, cualquier presunta 'revelación' suya en el orden del sentido y de los valores debe ser percibida y transmitida mediante testimonios humanos" (Segundo, 1991: 94). En este caso, del testigo humano que es Jesús de Nazaret. Así, creer en el Dios revelado por Jesús, no es solo creer en la existencia de un Ser superior sino, también, estar de acuerdo con los valores de los que da testimonio el mismo Jesús. Dicho de otro modo, en la fe de Jesús desplegada en su historia, podemos hallar claves -y no cualesquiera- para responder a la realidad que reclama salvación en el presente, como son las injusticias y desigualdades que atentan contra la dignidad humana.

No es este el lugar para presentar una pormenorizada aproximación histórica a Jesús de Nazaret, pero sí para destacar algunos elementos que nos permitan dar con los principales valores que orientan su existencia?. Para comenzar, acudimos al evangelio de Marcos, que nos presenta lo que sería una especie de síntesis del anuncio profético de Jesús: "El

9 Aparte de la obra de Juan Luis Segundo ya mencionada, en lo que sigue tendremos en cuenta a José Antonio Pagola (2007), Armand Puig (2008) y Jon Sobrino (1991). 
tiempo se ha cumplido y el Reino de Dios ha llegado; convertíos y creed en la Buena Nueva" (Mc 1,15). El centro del mensaje de Jesús, lo que da sentido a su vida y lo pone en misión se expresa con los términos Reino de Dios, o Reino de los cielos, según Mateo. Este reino o, mejor, reinado de Dios tiene una dimensión histórica y trascendente, estrechamente relacionadas: Jesús ora, enseña y espera que venga su Reino, que Dios haga su voluntad en la tierra como en el cielo, si atendemos a la versión mateana de la llamada oración del "Padrenuestro", que nos aporta un paralelismo explicativo (Mt 6,10). El ejercicio de la voluntad o soberanía de Dios en la tierra implica una transformación de toda la sociedad, de todas y todos los que conforman un pueblo; consistirá en que los hombres y mujeres recuperen la humanidad que han perdido de diversas maneras: "los ciegos ven y los cojos andan, los leprosos quedan limpios y los sordos oyen, los muertos resucitan y se anuncia a los pobres la Buena Nueva" (Mt 11,2-5).

En un contexto de grandes miserias, dolores y exclusiones, es claro que el reinado de Dios anunciado por Jesús tiene un destinatario específico, tiene una prioridad: "los pobres", aquellos "que lloran" y "tienen hambre" en Israel (Mt 5,3-6). En efecto, de acuerdo al estudio clásico de J. Dupont (1969), en la fuente "Q" que estaría detrás de las "bienaventuranzas" de Mateo y Lucas, son los pobres los invitados a alegrarse con el Reino que llega. Que el reinado de Dios constituya un "evangelio" para todos dependerá de un cambio de mentalidad ( $\mu \varepsilon \tau \dot{\alpha} v o \iota \alpha)$ que conlleva aceptar el cambio en la sociedad: "Y feliz aquél que no se escandalice de mí!” (Mt11,6); es decir, que no se oponga a Jesús porque trae una Buena Nueva a los pobres que hará a éstos felices. La prioridad del reinado de Dios anunciado por Jesús consistirá, entonces, en sacar a los pobres de la situación inhumana en que se encuentran. He ahí, pues, lo que parece ser el valor principal que moviliza a Jesús.

Jesús no solo anuncia el Reino, sino que también utiliza ciertas mediaciones (un "sistema de eficacia" o "ideología", en términos de Juan Luis Segundo) para implantar en la realidad aquello que da sentido a su vida, para hacer presente a los pobres y pecadores el amor predilecto de Dios. Además de recorrer distintos pueblos de la región de Galilea anunciando la buena nueva del Reino (ver Mt 4,23; Mc 1,39; Lc 4,14-15), se conmueve y reacciona ante el dolor de los enfermos, de los pobres y débiles (Mc 1,41; 6, 34; 9,22); pone a disposición de ellos su capacidad de aliviar males y sanar enfermedades. Jesús expulsa demonios, libera a las personas de aquellas fuerzas que les impiden ser dueñas de sí mismas, mostrando fehacientemente la victoria sobre el maligno que comporta el Reino. Jesús acoge a pecadoras y pecadores, come y habla con ellos, lo cual no solo libera de la propia esclavitud, sino que además devuelve la 
dignidad a quieren eran despreciados por los demás. Jesús da importancia a las comidas con toda clase de gente, le gusta hablar de banquetes, al punto que lo acusan de "comilón y borracho" (Mt 11,18-18). Estas comidas son anticipos y celebraciones gozosas del Reino. Más aún, come con los que nunca son invitados: con los pobres y marginados (Lc 14,1424). Llama también la atención el trato y amistad de Jesús con las mujeres, en un contexto cultural donde solo el varón era protagonista. Ellas son parte del grupo de los discípulos: María de Magdala, María la madre de Santiago y José, Salomé; sus amigas Marta y María. Es probable que haya habido algunas en la última cena, pero ciertamente estuvieron al pie de la cruz y fueron las primeras testigos de la resurrección (Pagola, 2007: 211-238). En fin, mediante todas estas acciones, podemos verificar nuevamente que restituir la vida digna de todo ser humano, partiendo por los pobres y marginados, constituye el valor supremo en la escala de valores de Jesús, a los que siguen valores como la libertad, la equidad en el trato, etc. Lejos de ser un idealista, Jesús se sirve de un sistema de eficacia para anticipar lo que el Reino generalizará con su llegada. El servicio a esos valores, que brotan desde la compasión o misericordia, es lo que mejor expresa o da cuenta del Dios del Reino (Sobrino, 1991: 125-127; ver también Kasper, 2013).

También en la línea de las mediaciones que utilizó Jesús para introducir eficazmente en la realidad la estructura de valores que constituye la manera como él concibe a Dios y lo que Dios quiere, habría que considerar su predicación. En particular, las parábolas. Mediante ellas, no solo explica mediante imágenes en qué consiste el Reino, sino que, además, enfrenta a aquellos que se oponen al Reino tal como Jesús lo entiende y práctica. Para Juan Luis Segundo, el hilo conductor de todas las discusiones críticas que encierran las parábolas es de orden político-religioso, así como era político-religiosa la autoridad que poseían los adversarios de Jesús. No podemos detenernos aquí en el sugerente análisis que hace este teólogo latinoamericano de más de 20 parábolas, en las que el carácter polémico se aprecia con mayor claridad (1991, pp. 186-232). Simplemente hay que señalar que una primera serie de parábolas están orientadas a desmantelar la falsa seguridad de aquellos que se sienten protegidos ante el Reino que viene, ya sea porque piensan que nada cambiará su situación material privilegiada (los ricos) o, bien, porque creen tener "derechos adquiridos" en cuanto autoridades delegadas por Dios. Una segunda serie, para destacar la alegría de Dios cuando logra recuperar para sí y para la sociedad de Israel, a cuantas y cuantos se hallaban perdidos, empobrecidos o marginados. Una tercera, para hacer ver que los verdaderos pecadores en Israel son aquellos que están en contradicción con el corazón de Dios, los que se oponen a la prioridad del amor de Dios por los 
pobres y pecadores; es decir, por los que estaban perdidos en Israel. En los fariseos y su teología verá Jesús el instrumento ideológico de que se valen las autoridades de Israel (sobre todo los sacerdotes que dominan en el Sanedrín) para mantener oprimido al pueblo y ejercer la marginación en provecho propio y en nombre de Dios. Por último, está la cuarta serie de parábolas, que tienen en común la solidaridad u opción por el pobre como "lugar" para la auténtica lectura o interpretación de la palabra de Dios. Esto, porque en Israel, la religión, en vez de permanecer al servicio de la obra de Dios -que es también promoción de la vida y del bien del ser humano- se había pervertido al convertirse en un absoluto (es decir, había adoptados los rasgos de una ideología patológica). Había olvidado que el sábado estaba hecho para el hombre y no el hombre para el sábado (ver Mc 2,27).

En fin, el Reino de Dios anunciado y anticipado por Jesús en un contexto conflictivo contempla distintos actores, a todos los cuales les invita a una conversión y a creer en la buena noticia: a los beneficiarios principales, los pobres y marginados, que crean que Dios los ama y desea liberarlos de sus males; a las discípulas y discípulos colaboradores, que como Jesús "busquen el Reino y su justicia” (Mt 6,33) y estén dispuestos a asumir la carga y consecuencias que ello implica (ver Mc 8,34-35; Mt 5,11-12 y par.); a los adversarios, que dejen de oprimir y poner pesadas cargas económicas, morales y religiosas sobre los demás.

En un determinado momento, las mediaciones o sistema de eficacia desplegado por Jesús en Galilea parecen no conseguir los efectos esperados. Luego de lo que algunos exégetas llaman "la crisis de Galilea", Jesús abandona su región y se pone en camino hacia Jerusalén (ver Mt 16,21) ${ }^{10}$. Detrás de todo esto pareciera verse a Jesús delante de una disyuntiva: por un lado, liberar a los pobres de la urgencia de sus necesidades, y, por otro, impedir que caigan en el inmediatismo ciego a lo que el Reino traerá en plenitud. Jesús rechaza ser reducido a un Mesías proveedor de milagros: decide subir a Jerusalén precisamente para que su anuncio se cumpla cabalmente, sin ambigüedades. En efecto, para Jesús, Jerusalén constituye algo decisivo: allí se sentirá muy pronto el poder de Dios que trae el Reino, como lo trajo en el pasado a ese mismo lugar. Ahora será con más poder y de manera definitiva. Pero Jesús sabe también que ir a

\footnotetext{
10 La "crisis de Galilea" ocurriría, según algunos exégetas, luego de la segunda multiplicación de los panes, estaría señalada por la confesión de Pedro, y sería seguida por la primera predicción de la pasión (ver Mc 8 y par.).
} 
Jerusalén es "subir" en el conflicto con los representantes oficiales de Dios que residen en esa ciudad ${ }^{11}$.

Finalmente, Jesús terminará su vida en Jerusalén con una sentencia política, ajusticiado por las autoridades romanas a instancias de las autoridades político-religiosas de Israel, como eran las del Sanedrín. Cabe destacar aquí que, entre las estrategias o sistema de eficacia de Jesús para implantar los valores del Reino, no contempló el uso de la violencia. Tampoco ésta fuera parte del dato trascendente que maneja Jesús de cómo ha de "venir con poder el Reino de Dios" (Mc. 9,1). Sin duda, no puede interpretarse como opción violenta el gesto profético en el templo (Mc 11,15ss y par.), con el cual, más bien, Jesús buscaba indicar cómo quiere estar Dios presente en el mundo. Jesús no promueve sino que, más bien, padece la violencia; "es crucificado porque su actuación y su mensaje sacuden de raíz ese sistema organizado al servicio de los más poderosos del Imperio romano y de la religión del Templo" (Pagola, 2007: 389). En lugar de responder con violencia, la muerte asumida por Jesús "fue el servicio último y supremo al proyecto de Dios, su máxima contribución a la salvación de todos" (Pagola, 2007: 352).

Obviamente, la última afirmación tiene que ver ya con la fe en Jesús. En efecto, la resurrección que sigue a su muerte en cruz es el punto de partida de la fe en Jesús, el Cristo, el Hijo de Dios, el Señor. Pero, también, la confirmación de la fe de Jesús: es decir, la certeza de que los valores por los cuales Jesús se jugó la vida no se pierden... Con el género literario que caracteriza a los relatos de la resurrección de Jesús se quiere comunicar el dato trascendente aportado por ese acontecimiento único que sobrepasa la historia: es el dato concreto sobre la forma en que Dios respondió a los valores practicados en la historia de Jesús. Estamos, pues, en el plano de lo escatológico, donde se juzga y verifica el sentido de la historia. Como dice Segundo, "la escatología a la que se asoman (las discípulas y discípulos) con esa profunda experiencia de Jesús resucitado constituye una especie de 'verificación en promesa' de que Dios hace suyos y, por ende, de la realidad entera, los valores que presenta la historia de Jesús" (Segundo, 1991: 330).

En definitiva, el Evangelio es una invitación a creer en el dato aportado por ese acontecimiento meta-histórico que es la resurrección: la promesa escatológica de que Dios hará suyos, como lo hizo con Jesús, todos nuestros trabajos y esfuerzos por construir un mundo más digno y humano, en la línea de lo que Jesús nos testimonia con su fe. Buscar que reine la justicia entre todos los seres humanos, responder con misericor-

11 Ver las tres predicciones de la pasión puestas en boca de Jesús a lo largo de su caminar hacia Jerusalén: Mc 8,31ss; 9,30ss; 10,32ss y par. respectivos. 
dia y de manera efectiva ante las miserias y distintas formas de marginación, poner medios que no contemplen la violencia parece ser lo espera Jesús de sus colaboradores y colaboradoras.

\subsection{La igualdad como derecho y la desigualdad como injusticia}

Pareciera que la igualdad, de la que habló San Pablo, tuvo que esperar hasta los tiempos de la Revolución francesa para que, al menos en Occidente, junto con la a libertad y fraternidad, fuera destacada como uno de los valores que han de configurar a nuestras sociedades. Por su parte, la Iglesia católica, en su apertura y diálogo con los valores destacados por la Modernidad, vuelve a poner atención en el valor de la igualdad y a denunciar lo que atenta contra ella. A modo de ejemplo, cabe citar los siguientes párrafos del Concilio Vaticano II (1965):

La igualdad fundamental entre todos los hombres exige un reconocimiento cada vez mayor. Porque todos ellos, dotados de alma racional y creados a imagen de Dios, tienen la misma naturaleza y el mismo origen. Y porque, redimidos por Cristo, disfrutan de la misma vocación y de idéntico destino. Es evidente que no todos los hombres son iguales en lo que toca a la capacidad física y a las cualidades intelectuales y morales. Sin embargo, toda forma de discriminación en los derechos fundamentales de la persona, ya sea social o cultural, por motivos de sexo, raza, color, condición social, lengua o religión, debe ser vencida y eliminada por ser contraria al plan divino. En verdad, es lamentable que los derechos fundamentales de la persona no estén todavía protegidos en la forma debida por todas partes. Es lo que sucede cuando se niega a la mujer el derecho de escoger libremente esposo y de abrazar el estado de vida que prefiera o se le impide tener acceso a una educación y a una cultura iguales a las que se conceden al hombre.

Más aún, aunque existen desigualdades justas entre los hombres, sin embargo, la igual dignidad de la persona exige que se llegue a una situación social más humana y más justa. Resulta escandaloso el hecho de las excesivas desigualdades económicas y sociales que se dan entre los miembros y los pueblos de una misma familia humana. Son contrarias a la justicia social, a la equidad, a la dignidad de la persona humana y a la paz social e internacional. (Gaudium et spes, n 29)

Vemos, pues, que la igualdad como derecho humano fundamental ha hallado "carta de ciudadanía" y un desarrollo teológico en el discurso social de la Iglesia. No es posible presentar aquí la evolución teológica y moral que ha tenido, en la enseñanza o doctrina social de la Iglesia (DSI), la comprensión del valor de la igualdad y su contracara, la desigualdad. 
En cambio, podemos señalar brevemente que, en el contexto latinoamericano, de modo sinodal y colegiado, la Iglesia de la región puso gran atención en las "desigualdades", en particular, en aquellas que calificaba de "injustas" o "excesivas". Más aún, podemos decir que hace más de cincuenta años dichas desigualdades fueron consideradas como el factor que más atentaba contra la paz y el desarrollo integral de América Latina. Para un desarrollo más pormenorizado este delicado asunto, me permito remitir a mi investigación teológico-cultural publicada recientemente, con ocasión del $50^{\circ}$ aniversario de la Conferencia de Medellín (Verdugo \& Arellano, 2019).

Al analizar el documento Paz de Medellín (CELAM, 1968) y describir los males destacados "en el mundo del texto", pudimos constatar que las desigualdades al interior de cada país y entre los países, si bien aparecen mencionadas en algunas ocasiones como un mal particular, subyacen también como código o norma que regula y mide todos los elementos que conforman el drama de América Latina. Así, por ejemplo, el problema de la distribución de los bienes y de los males configura "sectores" o "clases" dentro de las naciones o países, "centro" y "periferias" en el contexto internacional. La desigualdad económica divide a los sujetos entre sectores acomodados y sectores faltos de lo necesario, entre países pobres y países ricos; la desigualdad política o de relación con el poder divide entre sectores poderosos y sectores oprimidos, entre países imperialistas y países dependientes; la desigualdad cultural divide entre sectores que tienen gran participación en la cultura y sectores que viven en la ignorancia e impedidos de participar en ella, etc. Las desigualdades regulan y dan forma a todo el escenario y drama del relato o documento, y, por ende, constituyen un componente fundamental de la matriz cultural desde donde se comprende el subdesarrollo, el mal capital, y los demás males del relato que se oponen a la paz, el objeto-valor deseado. Es comprensible, entonces, que en un enunciado o sintagma que parece recapitular y sintetizar todos los males descritos, se afirme lo siguiente: "allí... donde existen injustas desigualdades entre hombres y naciones se atenta contra la paz". Situación que se interpreta teológicamente por los pastores, como "un rechazo del don de la paz del Señor", como "un rechazo del Señor mismo [Cf. Mt 25, 31-46]" (CELAM, 1968: n 14).

Ofrezco, nuevamente, el cuadro semiótico elaborado con ocasión de la investigación, que nos permite visualizar los valores y antivalores "elementales" en juego en la matriz cultural presente en Medellín: 


\section{Cuadro semiótico con los valores y antivalores "elementales" en la matriz cultural de Medellín}

\section{Desigualdades injustas}

\section{Paz}

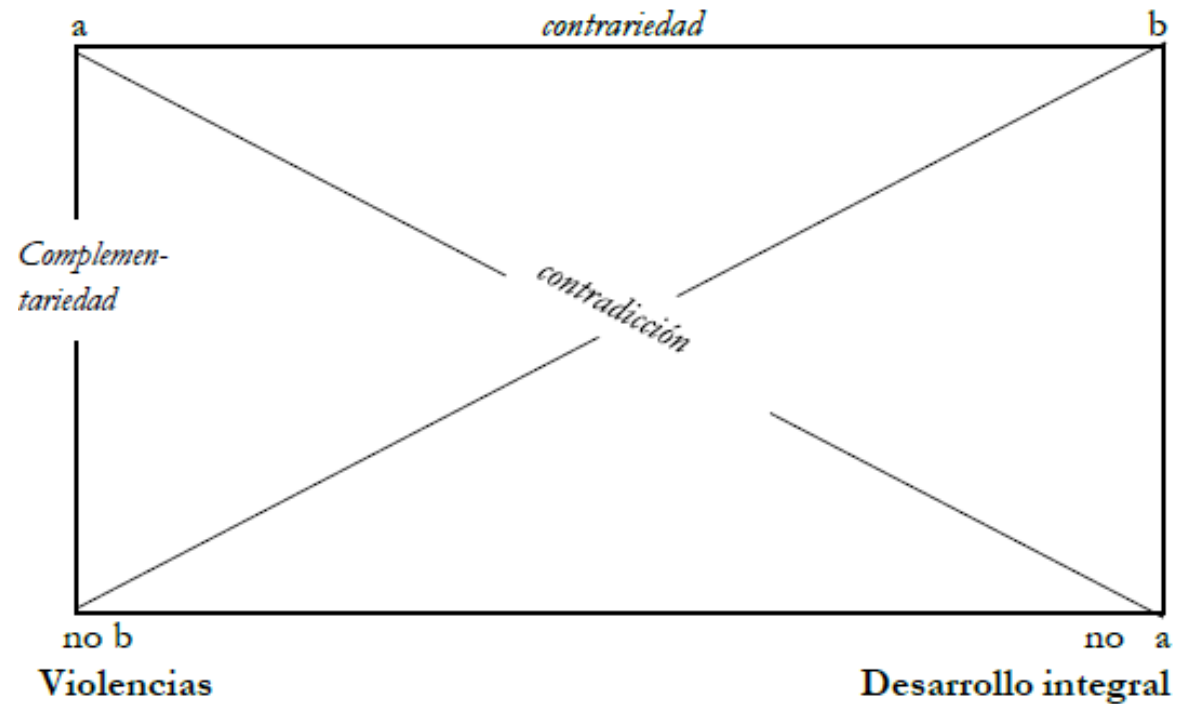

Como se puede apreciar, la matriz opone primariamente a las desigualdades injustas con la paz, y no con la violencia en cualquiera de sus expresiones, ya sea subversiva o represiva. Éstas encuentran su explicación en las desigualdades, así como el desarrollo integral permite entender cómo se entiende la paz en este escenario. No se trata simplemente de pasar de la violencia a la paz, sino de las desigualdades injustas a la paz, la cual comporta el desarrollo integral de todos en América Latina. Por lo visto, la lectura teológico-cultural de Medellín, puesta de relieve mediante la investigación, desgraciadamente sigue siendo pertinente en América Latina y en Chile, en particular. Digo "desgraciadamente", porque parece que hemos avanzado poco; digo, "pertinente", porque este discurso teológico-pastoral inculturado nos muestra un camino e itinerario aún por recorrer.

Para terminar, observemos que el papa Francisco, situado en la línea del Concilio Vaticano II y de Medellín, desde el comienzo de su pontificado ha llamado la atención acerca de las inequidades en cuanto detonantes de la violencia que afectan a nuestras sociedades, tanto entre naciones como al interior de ellas. En la exhortación apostólica Evangelii gaudium (2013), por ejemplo, advierte: “...hasta que no se reviertan la exclusión y la inequidad dentro de una sociedad y entre los distintos pueblos será imposible erradicar la violencia" (EG, $\left.n^{\circ} 59\right)$. Más tarde, en la encíclica 
Laudato si (2015), en un tono crítico hacia el modelo económico globalizado, el Papa afirmará que "la visión que consolida la arbitrariedad del más fuerte ha propiciado inmensas desigualdades, injusticias y violencia para la mayoría de la humanidad, porque los recursos pasan a ser del primero que llega o del que tiene más poder: el ganador se lleva todo" (LS, $n^{\circ}$ 82). Los procesos de degradación ambiental, afirma allí mismo, afectan de tal manera que profundizan las injustas desigualdades, constituyen una fuente de iniquidad, pues "el ambiente humano y el ambiente natural se degradan juntos" ( $\left.\mathrm{n}^{\circ} 48\right)$. "El desafío urgente de proteger nuestra casa común - dirá Francisco- incluye la preocupación de unir a toda la familia humana en la búsqueda de un desarrollo sostenible e integral, pues sabemos que las cosas pueden cambiar" ( $\left.{ }^{\circ} 13\right)$. En la encíclica Fratelli Tutti (2020), recién publicada, es posible reconocer los mismos valores y antivalores "elementales" en juego en la matriz cultural presente en Medellín, en continuidad con el Vaticano II y otros documentos de la DSI. A modo de ejemplo, cito uno de los siete párrafos donde aparece el significante "inequidad":

Quienes pretenden pacificar a una sociedad no deben olvidar que la inequidad y la falta de un desarrollo humano integral no permiten generar pa\%. En efecto, 'sin igualdad de oportunidades, las diversas formas de agresión y de guerra encontrarán un caldo de cultivo que tarde o temprano provocará su explosión. Cuando la sociedad — local, nacional o mundial — abandona en la periferia una parte de sí misma, no habrá programas políticos ni recursos policiales o de inteligencia que puedan asegurar indefinidamente la tranquilidad'. Si hay que volver a empezar, siempre será desde los últimos. (FT, n ${ }^{\circ}$ 235. Las cursivas son nuestras)

\section{REFLEXIONES FINALES}

Luego del breve recorrido teológico, propongo algunas reflexiones finales que quieren ser una contribución al debate en torno a las desigualdades que hieren la convivencia humana, a nivel global y local, y que demandan una urgente respuesta que nos conduzcan a una paz basada en la justicia.

Tenemos que reconocer, primer lugar, que de los valores "revelados" por Jesús mediante sus palabras y obras, al anunciar y anticipar en su contexto el Reino de Dios, permanecen vigentes y reclaman ser implantados con urgencia en la realidad global y local. Más aún, son parte constitutiva de la misión de las discípulas y los discípulos de Jesús, de los llamados a colaboran con él en la búsqueda del Reino y su justicia, en 
cada tiempo y lugar. Se trata, pues, de que la fe de Jesús continúe en nuestra historia.

En segundo lugar, la igualdad (íó $\rceil \eta \varsigma)$, comprendida germinalmente por San Pablo - desde la fe en Jesucristo- como uno de los valores que han de reinar entre todos, urge ser puesta de relieve, sobre todo cuando pareciera que lo que reina es la desigualdad en sus múltiples dimensiones que hieren a los herederos de Dios, y a la creación entera, que también gime esperando que se manifieste -por la acción del Espíritu- la gloriosa libertad de las hijas e hijos de Dios (ver Rom 8). Hacer frente a las desigualdades o inequidades que hieren la convivencia humana y destruyen nuestro planeta, requieren de la promoción de valores tan evangélicos como, la justicia, la libertad, la inclusión... y la igualdad, relevada por el apóstol.

Además de rescatar los valores de Jesús como lo hizo Pablo, es necesario, en tercer lugar, considerar una y otra vez qué sistemas de eficacia pueden contribuir a hacerlos posible. Se requiere del discernimiento de las mediaciones que hacen efectivos dichos valores. En efecto, las "ideologías" no han muerto; están vivas y son necesarias, como mediaciones para la acción (Verdugo, 1992). No es de extrañar, pues, como lo hemos visto en los análisis sociales reseñados en la primera parte de este trabajo, la prioridad que debe dársele a la discusión ideológica y política. Esta es ineludible si no queremos, por una parte, caer en un idealismo ineficaz o, por otra, en la violencia que solo trae más violencia.

Cabe preguntarse, por último, si el valor de la igualdad no podría ser mejor promovido por parte de la Iglesia católica, en su servicio al mundo, si no se abordan, por ejemplo, las inequidades en la forma de sostener roles y la distribución del poder al interior de ella (Castillo, 2017). Parece ser esa una de las preocupaciones del papa Francisco (2013), cuando al comenzar su pontificado afirmó que "todavía es necesario ampliar los espacios para una presencia femenina más incisiva en la Iglesia. Porque 'el genio femenino es necesario en todas las expresiones de la vida social; por ello, se ha de garantizar la presencia de las mujeres también en el ámbito laboral' y en los diversos lugares donde se toman las decisiones importantes, tanto en la Iglesia como en las estructuras sociales" (EG, n $\left.{ }^{\circ} 103\right)$. Sin duda, las desigualdades internas al interior de la Iglesia mellan su credibilidad; dificultan que ella pueda tener una palabra profética más convincente en relación a las desigualdades o inequidades en la sociedad, promoviendo así un Reino de justicia y equidad. 


\section{REFERENCIAS}

Castillo, J. M. (2017). Teología de la desigualdad. Periodista Digital. 24 de febrero. Disponible en https://www.periodistadigital.com/cultura/religion/20170224/teologiadesigualdad-noticia-689400311790/

CELAM. (1968). Medellín. Conclusiones: La Iglesia en la actual transformación de América Latina a la luz del Concilio. Santiago: Ediciones Paulinas.

Concilio Vaticano II. (1965). Gaudium et spes. Disponible en http://www.vatican.va/archive/hist_councils/ii_vatican_council/docume nts/vat-ii_const_19651207_gaudium-et-spes_sp.html

Dupont, D. J. (1969). Les béatitudes. (T.I). Paris: J. Gabalda.

Francisco. (2013). Evangelii Gaudium: Exhortación Apostólica sobre el anuncio del Evangelio en el mundo actual. Disponible en http://www.vatican.va/content/francesco/es/apost_exhortations/docum ents/papa-francesco_esortazione-ap_20131124_evangelii-gaudium.html

Francisco. (2015). Laudato si: Carta encíclica sobre el cuidado de la casa común. Disponible

http://www.vatican.va/content/francesco/es/encyclicals/documents/pap a-francesco_20150524_enciclica-laudato-si.html

Fuentes, F. (2020). Walter Scheidel, historiador de la Universidad de Stanford: "A corto plazo, es probable que la pandemia aumente la desigualdad". La Tercera, 15 de junio. Disponible en https://www.latercera.com/mundo/noticia/walter-scheidel-historiadorde-la-universidad-de-stanford-a-corto-plazo-es-probable-que-la-pandemiaaumente-la-desigualdad/N45LZOHRGFD6FEIYZSRGHGX5WQ/

González Faus, J. I. (2015). ¿El capital contra el siglo XXI?: Comentario teológico al libro de Thomas Piketty. Maliaño (Cantabria): Sal Terrae.

Kasper, W. (2013). La misericordia: Clave del evangelio y de la vida cristiana. Santander: Sal Terrae.

Pagola, J. A. (2007). Jesús: Una aproximación histórica. Boadilla del Monte (Madrid): PPC.

Piketty, T. (2014). El capital en el siglo XXI. México, DF: Fondo de Cultura Económica.

Piketty, T. (2019). Capital e ideología. Bogotá: Editorial Planeta Colombiana.

PNUD Chile. (2017). Desiguales. Orígenes, cambios y desafíos de la brecha social en Chile (Sintesis). Disponible en https://www.cl.undp.org/content/chile/es/home/library/poverty/desigu ales--origenes--cambios-y-desafios-de-la-brecha-social-en-.html

Puig i Tàrrech, A. (2008). Jesús una biografía. Buenos Aires: Edhasa.

Scheidel, W. (2018). El gran nivelador: Violencia e historia de la desigualdad desde la Edad de Piedra hasta el siglo XXI. Barcelona: Crítica.

Segundo, J. L. (1991). La historia perdida y recuperada de Jesús de Nazaret. De los sinópticos a Pablo. Santander: Ed. Sal Terrae. 
Sobrino, J. (1991). Jesucristo liberador: Lectura histórico-teológica de Jesús de Nazaret. Madrid: Editorial Trotta.

Verdugo, F. (1992). El desafío vigente de las ideologías. Mensaje, 41(407), 65-69.

Verdugo, F. (2015). Perspectivas teológicas de la encíclica Laudato Si': Contribución a la IV Semana Teológica en la UCN. Cuadernos de Teología, 7(2), 136-157.

Verdugo, F. (2016). La educación teológica en el contexto latinoamericano: Los aportes de Juan Luis Segundo. Teología y vida, 57(4), 485-507.

Verdugo, F. (2018). Relectura de Medellín: Desafíos actuales para la Teología. Teología y vida, 59(1), 111-128.

Verdugo, F., \& Arellano, T. (2019). Desigualdad, violencia y paz en la conferencia de Medellín Perspectiva teológico-cultural. Teología y vida, 60(3), 321366. 